\title{
Miradas "noir" de Barcelona: desde Vázquez Montalbán y Mendoza a Riera
}

\author{
Emilio RAMÓN GARCÍA \\ Universidad Católica de Valencia \\ emilio.ramon@ucv.es
}

\begin{abstract}
RESUMEN
La resolución de los crímenes investigados pasa a segundo plano en la novela negra española, que opta por reforzar la simbiosis entre el género policial y la crítica social. Manuel Vázquez Montalbán y Eduardo Mendoza ofrecen una visión fragmentaria de Barcelona, un retrato descarnado de la clase trabajadora, del futuro de la juventud y de la especulación. El primero, obsesionado con evitar que el progreso y la globalización arrasen con la historia de los más humildes, hace que su personaje estrella, angustiado por la crisis de valores, abandone la ciudad. Para Mendoza, Barcelona se convierte en metáfora de la conciencia política y del poder, y prefiere revelar las tensiones del progreso y del capitalismo sirviéndose de un pícaro loco y solitario carente de un código de conducta superior. Carme Riera, preocupada por la actual crisis de valores, asume la tradición novelística pero con variaciones en, por ejemplo, los paisajes, la educación, los jóvenes, la policía o los que ostentan algún estatus social, rompiendo estereotipos en su ópera prima en el género.
\end{abstract}

Palabras clave: Novela negra, crítica social, urbanización de la conciencia, crisis de valores

\begin{abstract}
Casting contemporary events in an incriminating light, the detective novel genre in Spain pays more attention to the social portrait than to solving the mystery. Manuel Vázquez Montalbán and Eduardo Mendoza present their readers with a fragmented world, an incriminating view of the social reality in Barcelona which focuses on the working class, the lack of hope for the youth and the exploitation by the rich and powerful. The first one, obsessed with the dynamics of the urban process, its inner tensions, and the impact of the evolution of capitalism on the historic memory of the lower classes, makes his detective leave town. Mendoza explores the relationship between the human mind and the urban environment, which turns out to be a metaphor for a site or container of power. His detective, a mad "pícaro", refuses to follow any norm of conduct, unlike Marlow or Spade. Carme Riera, in her debut in this genre, acknowledges her predecessors, but opts to provide the reader with some new insights. Riera, concerned with today's lack of moral and social
\end{abstract}


values, breaks with a number of stereotypes, such as locations, the educational system, the youth, the police, or those with some sort of social status.

Key words: Detective novel, social critic, urbanization of conscience, lack of values

\section{El género criminal en España}

Las novelas de detectives publicadas por escritores españoles empezaron a proliferar hacia finales de 1970, bebiendo de una tradición iniciada en los cincuenta $^{1}$. Muestra clara de este gran auge son, entre otras, las obras de Jaume Fuster, Juan Madrid, Andreu Martín, Manuel Vázquez Montalbán, Eduardo Mendoza, Fernando Savater, o Juan Benet, al igual que libros y números extra de crítica especializada dedicados a la novela negra como Los Cuadernos del Norte de 1979 ó 1983, o los trabajos de Colmeiro y de Rob Rix, por mencionar alguno. Autores y crítica coinciden en considerar la novela negra como un reflejo de la sociedad que representa, una toma del pulso del país en que se publica, y «una correspondencia entre la modernidad del género y el papel de la ciudad como motor de la modernización» ${ }^{2}$, siendo en este sentido donde la novela de detectives española merece especial atención, tanto por su auge, como por sus particularidades. Una de éstas consiste en «recycling the formulaic conventions of American hard-boiled fiction, these narratives tend to put political and social change under the suspicious gaze of private detectives whose skepticism sharply contrasts with the public display of self-congratulatory optimism of political leaders and institutions» ${ }^{3}$. No se trata de una mera imitación del género, sino de una transformación significativa del mismo, particularmente en lo que a parodia e ironía se refiere. Es por ello que muchas veces los críticos argumentan que las novelas no son propiamente novelas de detectives, en el sentido estricto del término, puesto que los crímenes investigados se quedan muchas veces en segundo plano, sino, más bien, una mirada irónica y, en ocasiones, triste a la sociedad española. Patricia Hart duda incluso del aspecto detectivesco de la serie Carvalho, «because one senses deep down that in their hearts, the books do not really want to be detective novels. Rather, they want to be commentaries about the problems of living in contemporary

\footnotetext{
${ }^{1}$ R. Tasis inició sus obras policíacas a mediados de los años cincuenta adaptando numerosos estereotipos de personajes de la narrativa norteamericana de los años treinta. Dicha tradición la continuó Manuel de Pedrolo en la década de los sesenta a quien, al éxito de sus novelas, hay que sumarle la gran importancia de la colección criminal La Cua de Palla, que, bajo su dirección, introdujo en Barcelona todo este tipo de narrativa, convirtiéndose en la colección de España que más títulos ha publicado hasta la actualidad.

2 J. R. Resina (1997), p. 144.

${ }^{3}$ M. Santana (2000), p. 535.
} 
Spain ${ }^{4}$, no obstante, la novela de detective y el comentario político social no se auto excluyen 5 .

\section{Barcelona como escena del crimen}

La fascinación de Barcelona como escenario para un crimen se remonta a los años veinte, cuando escritores y periodistas catalanes comentaban la degradación y promiscuidad al margen de la ciudad burguesa en el semanario satírico El escándalo con el nombre de «barrio chino», en referencia al Chinatown de San Francisco ${ }^{6}$. Al tratarse de una ciudad que se transformó radicalmente con la revolución industrial, con las complejidades y los conflictos que eso conlleva ${ }^{7}$, con una gran densidad demográfica y con un definido carácter marítimo, lugar de tránsito de todo tipo de personas y de productos, Barcelona se erige así como lugar privilegiado para esta literatura y, en los años setenta, primero Jaume Fuster en lengua catalana y después Manuel Vázquez Montalbán en castellano, la presentan como una de las grandes protagonistas ${ }^{8}$. Una ciudad que ha sabido conjugar su presente con su pasado mostrando un escenario «lleno de barricadas, putas de absenta, Gaudís, sufrimientos éticos, ricos ligeros, pobres sólidos, ocupantes, ocupados, humillados, ofendidos... y todo en un decorado lleno de maravillas pequeñitas y cercanas, a veinte minutos las putas de absenta de los señores del Jardinets» ${ }^{9}$. Su idoneidad para el género la han sabido explotar escritores como Francisco González Ledesma ${ }^{10} \mathrm{o}$ Andreu Martín, dándole al espacio y al tiempo barcelonés gran protagonismo.

Como protagonista en el tiempo, Barcelona se torna escenario de violentas luchas entre el proletariado y la burguesía en novelas como La verdad sobre el caso Savolta (1975) de Eduardo Mendoza o Guardo el Confident (1985) de Llorenç Sant

\footnotetext{
${ }^{4}$ P. Hart (1987), p. 86.

${ }^{5}$ M. Santana (2000), p. 536.

${ }^{6}$ D. Boatwright y E. Da Cal (1984), p. 26.

${ }^{7}$ Tasis afirmaba que «Barcelona era la ciudad del mundo donde había habido más revueltas, más huelgas generales, más barricadas, más quemas de iglesias y conventos, más bombas, más atentados anarquistas y reaccionarios, más levantamientos y más represiones, hospedaba en aquel barrio todo un sector especial, entre iluminado y aprovechador, que vivía al margen de las luchas sociales, y la policía se tenía que enfrentar demasiado a menudo» R. Tasis, (1994), p. 35.

${ }^{8}$ Fuster con títulos como De mica en mica s'omple la pica (1972) y Sota el signe de sagitari (1984), entre otras. Montalbán, por su parte, dedica casi todo su ciclo de Pepe Carvalho empezando por Tatuaje (1974) y terminando con las novelas póstumas Milenio I: Rumbo a Kabul (2004 a) y Milenio II; En las antipodas (2004c), salvo algunas excepciones.

${ }^{9}$ Cassani (2000), p. 11.

10 Expediente Barcelona (1983), Las calles de nuestros padres (1984) y las premiadas Crónica sentimental en rojo (1984) o Una historia de barrio (2007) son unos excelentes retratos de los barrios viejos de la ciudad.
} 
Marc, campo del tráfico de drogas, chantajes y prostitución en Barcelona Connection (1988), reflejo de la llegada del turismo, la emigración interior y el conflicto inmobiliario como en De mica en mica s'omple la pica (1972) de Jaume Fuster o Los mares del Sur (1979) de Manuel Vázquez Montalbán ${ }^{11}$. La adjudicación de los Juegos Olímpicos supone para Barcelona una profunda transformación, por ejemplo, el derribo de una parte importante de los escenarios que habían sido tan comunes en estas novelas. A partir de este momento, el desencanto, al igual que ocurre en la sociedad contemporánea, se convierte en tónica general ${ }^{12}$. Entre la pléyade de escritores que han tomado a Barcelona como protagonista, dos brillan con luz propia tanto por la aceptación de la crítica como del gran público: Manuel Vázquez Montalbán y Eduardo Mendoza. Ambos escritores miran al pasado y al presente de la ciudad de Barcelona como una proyección actual de la ciudad en la que viven, uno con una visión más politizada, otro con una visión más irónica y desapasionada, pero siempre ironizando sobre el imparable avance del progreso. No en vano, el propio Vázquez Montalbán nos recuerda la «identidad entre esta apropiación poética y la poética que mejor traduce el talante de una época» ${ }^{13}$ : el retrato social. Con una larga y ampliamente estudiada travesía de los múltiples retratos de la ciudad condal que ambos han prodigado, la pregunta que nos atañe es si la Barcelona que muestra Carme Riera en su primera novela de detectives sigue una evolución respecto a estos o si, por el contrario, le imprime un carácter especial. Tras un repaso por las miradas sobre Barcelona de los dos autores, analizaremos cómo es este nuevo retrato de la urbe que nos pinta Riera.

\section{La Barcelona de Manuel Vázquez Montalbán}

Vázquez Montalbán comienza su andadura en la novela negra con Tatuaje, en donde continúa con la ironía, el escepticismo y el collage que le caracterizaban, pero mostrando una «voluntad de contar una historia, argumento, personajes, tramaintriga ${ }^{14}$ que antes se diluía en su afán experimental. Las primeras siete novelas de la serie Carvalho, de 1972 a 1984, reflejan fielmente la realidad política y social de una época marcada, entre otras cosas, por la transición, el pelotazo urbanístico y una inestabilidad social que afecta especialmente a los más desfavorecidos. A partir de La soledad del manager, obra en la que presenta formalmente al detective Pepe Carvalho, quien ya apareciera en su novela experimental Yo maté a Kennedy,

\footnotetext{
${ }^{11}$ A. Martín Escribà, (2009), p. 45-46.

${ }^{12}$ Pese a ser un mundo mayormente masculino, Martín Escribà señala que la escritora Alicia Giménez-Barlett, con su detective Petra Delicado, también entró a formar parte de este universo barcelonés con novelas como Ritos de muerte (1996), Día de perros (1997), Mensajeros de la oscuridad (1999), Muertos de papel (2000) o Un barco cargado de arroz (2004).

${ }^{13}$ M. Vázquez Montalbán (1987 a), «Regalo» p. 23.

${ }^{14}$ E. Ramón García (2007), pp. 124-5.
} 
Vázquez Montalbán logra enganchar a un amplio número de lectores apoyándose en las posibilidades y atractivos del género, donde, según sus palabras, «se subsumía los contenidos de crítica social» de los defenestrados realismos ${ }^{15}$. Se posiciona así del lado de los más desfavorecidos para minar la posición de la clase gobernante a través de las pesquisas del pintoresco detective siguiendo una postura Gramsciana de la novela detectivesca la cual elude los sistema de control de la burguesía «such as control of publishing houses and the popular press, by appealing directly and simply to the worker's taste in entertainment. The hope is that a group of socialist intellectual writers can raise the consciousness of the masses in the way that respected artists, like Dostoyevsky and Chesterton, improve in the work of Eugène Sue and Conan Doyle respectively» ${ }^{16}$. En esta línea, el propio escritor comentaba en una entrevista con Quim Aranda que recuperar la memoria del Raval y del Barri Xino, los barrios de los trabajadores, se había convertido en un imperativo pues a esta gente nadie le explica lo que pasa ni tampoco goza de «un llenguatge ni la possibilitat de construir la seva èpica. Jo, però, sóc un d'ells $i$ he arribat a uns nivells en què puc explicar i reflectir tot això. I sí que la tinc, aquesta responsabilitat... jo sí que sento la necessitat de parlar d'aquella gent, que és la meva. I si no ho fes, em faria l'efecte que els tornaria a matar» ${ }^{17}$. Su descripción de Barcelona no pretende, por tanto, proporcionar un retrato global de la ciudad, sino una representación de aquellas áreas que permanecen ocultas al público y al discurso social. La clase media catalán-parlante no es, por ese motivo, la que entra en juego aquí, pese a las quejas de Joan Ramón Resina ${ }^{18}$, sino que se vuelca en aquellas zonas en que «la composició sociopolítica del carrer era tota de vençuts» ${ }^{19}$, adoptando uno de los rasgos característicos de la novela de detectives tal y como la plantea Jameson a propósito de Raymond Chandler y su detective privado: «an involuntary explorer of the society, Marlowe visits either tose places you don't look at or those you can't look at: the anonymous or the wealthy and secretive» ${ }^{20}$. Esta manera de explorar la sociedad es similar a la que se da en la novela picaresca, pues ambas prestan atención a la «fragmentation of the world, and an incriminating view of social reality -as their emphasis on narrating a case indicates ${ }^{21}$. El detective nos revela aquella parte de la sociedad en peligro de quedar oculta, ya sea por cuestiones de marginalización (las zonas inmigrantes), de secretismo (la alta burguesía) o de pérdida de memoria (especialmente la histórica). De hecho, si nos fijamos en el recorrido que hace Carvalho por la ciudad de Barcelona en Los mares

${ }^{15}$ D. A. Forgacs (1988), p. 297.

${ }^{16}$ D. A. Forgacs (1988), p. 297.

${ }^{17}$ Q. Aranda (1995), p. 21-22.

${ }^{18}$ J. R. Resina (1997)

${ }^{19}$ M. Vázquez Montalbán \& Jaume Fuster (1985), p. 31.

${ }^{20}$ F. Jameson (1981), p. 128.

${ }^{21}$ M. Santana (2000), p. 542. 
del Sur, pese a la sensación inicial de que el detective deambula por toda la ciudad para resolver el misterio de la muerte de Pedrell, la novela discurre, en realidad, por una zona muy concreta. Comienza en Sant Andreu, donde se descubre el cuerpo del empresario y, a mitad de la novela, las pesquisas del detective le llevarán al lado opuesto de la ciudad: al ficticio barrio de San Magín. Por el camino, ha pasado de las zonas humildes de la Ciutat Vella a las residencias exclusivas de la alta burguesía en Sarrià-Sant Gervasi en una especie de recorrido en Y sobre el mapa real de la ciudad, con la excepción del imaginado barrio. No es coincidencia que dos de los aspectos con los que la novela se muestra más crítica, la falta de futuro para los jóvenes más desfavorecidos y la especulación por parte de los que más tienen, vengan acompañados de dos asesinatos y de falta de escrúpulos por parte de los especuladores: «Yo subrayo lo que ha dicho Isidro, señor Carvalho. Si yo fuera un urbanista, probablemente recomendaría demoler San Magín. Pero desgraciadamente no es posible. Un escándalo sólo serviría para perjudicar al señor Planas y a mí. Yo utilicé mi influencia con el presidente del Área Metropolitana para conseguir permisos casi imposibles. Un caso claro de especulación que no oculto ni del que me avergüenzo» ${ }^{22}$. Como contrapartida, en San Magín aparece el cadáver de una joven vestida como Olivia Newton-John en la película Grease, conectando así ambas problemáticas. Vázquez Montalbán rechaza la posibilidad de embellecer una identidad imaginada o falsa de las zonas desfavorecidas, él recrea un Barri Xino contrapuesto a las representaciones exóticas de escritores como Jean Genet o Pierre de Mandiargues y muestra descarnadamente su falta de recursos y de un futuro digno, al tiempo que evoca con cierta nostalgia «aquellos tiempos en que su madre asaba las castañas en una sartén agujereada, todavía en el fuego de carbón mediocre de la posguerra o de bolas de polvo de carbón, a la luz del carburo, aún a ciegas eléctricas en aquel barrio de la ciudad vieja ahora amenazado por las buenas y malas intenciones de la posmodernidad $»^{23}$.

La serie Carvalho proporciona no sólo una historia de la Barcelona de la clase trabajadora, «La ciudad se sumergía en la tregua del mediodía y el chirrido de las puertas metálicas de los comercios clausuraba la mañana laborable» ${ }^{24}$, sino también una clara preocupación, que se convertiría en obsesión, por conseguir que ésta no caiga en el olvido, por evitar que el avance inexorable del tiempo, del progreso y de la globalización, arrasen con su pasado. Posibilita un diálogo entre el pasado y el presente en el que Carvalho nos abre las puertas a una ciudad muy vivida; un alter ego que le posibilitaba «solucionar un problema que en la novela me atormentaba mucho, que era el problema de a través de quién se ve el mundo. Entonces a través de la aparición de Carvalho me di cuenta de que a él le podía delegar la función de

\footnotetext{
${ }^{22}$ M. Vázquez Montalbán (1979), pp. 191-2.

${ }^{23}$ M. Vázquez Montalbán (1991), p. 115.

${ }^{24}$ M. Vázquez Montalbán (1974), p. 11.
} 
ver la vida. Personalmente, estaba agotado de hacerlo. Entonces era "él" quien veía, opinaba, juzgaba y sancionaba» ${ }^{25}$ y lo hace con conciencia social y un más que considerable bagaje cultural que «llevaba encima como el caracol que llevaba su cáscara» ${ }^{26}$. Así nos encontramos con numerosas referencias a la infancia y a la juventud del detective, a

\begin{abstract}
A la calle de la Cera ancha entre gitanos que habían trasladado sus taburetes y carajillos a los bares de la Ronda y de la esquina con la calle Salvadors. Eran los mismos o hijos de los mismos que él había visto bailar y sobrevivir en las puertas del Moderno o del Alujas, en los años cuarenta, desde el balcón de una casa construida en 1846, dos años antes de la publicación del Manifiesto Comunista, en un evidente gesto de optimismo histórico por parte del constructor ... barrio desnudo desde que habían desaparecido las estraperlistas callejeras y Pepa la Rifadora, sin otras supervivencias heroicas que la de la fuente de El Padró, la capilla románica a medio descubrir entre un colegio de un barrio y una sastrería, con el ábside en otro tiempo repartido entre un estanco y un herrero y la no menos superviviente casa de condones La Pajarita, declarable de interés nacional o monumento histórico. ${ }^{27}$
\end{abstract}

Su bagaje cultural coincide con el del propio escritor, quien naciera en una familia de inmigrantes en un área humilde de la ciudad donde convivían los perdedores, comenta Satué, de la realidad catalana, los foráneos ${ }^{28}$. Carvalho tiene su oficina en la Rambla de Santa Mónica, en el corazón del Barri Xino, cerca de donde él creció, en un inmueble antiguo que antiguamente fue casa de citas y que ahora se había convertido en una «colmena de despachos de industrias menores: fabricantes de colonia por libra, abogado de vicetiples y pequeños hampones, un gestor, un periodista ansioso de hundirse en los fondos del Barrio Chino para escribir una novela de realismo urbano, una vieja callista, una modista, una mini peluquería para clientas habituales desde la Exposición de 1929, algún que otro estudio habitado por pelotaris del frontón Colón y chicos del conjunto Barcelona de Noche» ${ }^{29}$. Su ayudante Biscúter es un ex-prisionero que vive en la oficina y le prepara comidas, mientras que Bromuro, el limpiabotas, le sirve de informante. Completa el pintoresco grupo la novia del detective, la cual trabaja de prostituta en su propio apartamento. Todos viven por la zona «que empezaba en el puerto y desembocaba en la enorme mediocridad de la plaza de Cataluña. Las Ramblas habían conservado el sabio capricho de las aguas con destino, $[. .$.$] edificios que marcaban tres siglos$

\footnotetext{
${ }^{25}$ P. Hart (1987), p. 21.

${ }^{26}$ M. Vázquez Montalbán (1977), p. 112.

${ }^{27}$ M. Vázquez Montalbán (1977), pp. 33-4. El propio escritor comenta acerca de todos esos lugares en su infancia y de cómo fue la misma en sus Diàlegs a Barcelona con Joan Fuster.

${ }^{28}$ E. Ramón García (2007), p. 122.

${ }^{29}$ M. Vázquez Montalbán (1977), p. 23.
} 
de historia de una ciudad con historia. Carvalho amaba aquel paseo como amaba su vida, porque le parecía insustituible» ${ }^{30}$. El placer que encuentra por las Ramblas, en comer tapas en los bares de la Plaça Reial y en deambular por el laberinto del mercado de la Boquería, le proporciona una sensación de permanencia y de identidad que le cuesta cada vez más encontrar en otras partes, por lo que sus pesquisas van siempre acompañadas de un diálogo entre el pasado y el presente de la ciudad para que no se olvide «la memoria de aquellos tiempos y de aquella gentes» ${ }^{31}$ y para denunciar la injusticia social, como explica Pugovel: «this new breed of crime story insisted on casting contemporary events in an incriminating light $\rangle^{32}$. Por eso no es de extrañar que, independientemente de quién le haya contratado o de dónde se hubiera cometido el crimen, al final, «casi todos mis clientes están en la zona alta y sus víctimas en la zona baja» ${ }^{33}$. Desde Vallvidrera, donde tiene su casa, Carvalho disfruta de un lugar estratégico, como si de una torre vigía se tratase, desde la que ve: «madre, la mierda flotante que se ve en esta ciudad ${ }^{34}$. Gracias a su posición de espectador privilegiado, viviendo en una de las mejores zonas y trabajando en una de las peor paradas, el detective desenmascara los procesos de maquillaje de la realidad que lleva a cabo la burguesía para, en nombre del progreso, cometer sus excesos, como expone el presidente del F. C. Barcelona Bastè de Linyola en su defensa de los cambios que sufrirán el Raval y el Barri Xino en preparación de los Juegos Olímpicos:

Hay que aceptar la buena y la mala herencia del pasado y practicar un urbanismo y una arquitectura de dignificar lo dignificable y derruir sólo lo estrictamente destruible... esta ciudad será el escaparate de Cataluña y de España en mil novecientos noventa y dos y está en juego una imagen publicitaria en el gran mercado universal de la imagen. $\mathrm{Y}$ eso hay que hacerlo con seriedad y responsabilidad democráticas. Sin dejarnos conducir por la aventura especulativa, pero tampoco dejándonos paralizar por un conservadurismo pusilánime que en ocasiones adquiere coartada o disfraz de pensamiento progresista, de pensamiento de izquierda... Esta ciudad puede crecer o paralizarse y eso depende de que con la coartada de vigilar la especulación, de defender a la ciudad de los especuladores, se pase por el rasero de la suspicacia, de la sospecha, toda iniciativa de crecimiento y se caiga en la peor de las tesituras: ni hacer ni dejar hacer. El pensamiento crítico tiene su tiempo y cuando se prolonga más de lo

\footnotetext{
${ }^{30}$ M. Vázquez Montalbán (1974), pp. 152-3.

${ }^{31}$ M. Vázquez Montalbán (1977), p. 90.

${ }^{32}$ S. P. Pugovel (1987), p. 535.

${ }^{33}$ M. Vázquez Montalbán (1987c) Asesinato, p. 107.

${ }^{34}$ M. Vázquez Montalbán (1987c) Asesinato, p. 63.
} 
necesario se convierte en un obstáculo fiscalizador que acaba inutilizándose a sí mismo porque ni alienta ni impide lo nuevo. ${ }^{35}$

Esta postura maniquea, atizando el miedo a paralizar el progreso, busca desestabilizar cualquier intento de protesta. La sociedad deja así atrás las ideas fuertes, las ideologías del pasado, y se rinde a los cantos de sirena del «triunfo del presente, de lo inmediato» ${ }^{36}$, posibilitando una especulación cuyos efectos aún se sienten. Conforme avanzamos en la serie, Carvalho se encuentra cada vez más afectado por los cambios radicales que está experimentando la ciudad. Al igual que hicieran escritores como Félix de Azúa, Francisco Umbral y Manuel Vicent, el escritor catalán se muestra cada vez más preocupado por la erosión de la memoria histórica en pro de un progreso deshumanizador: «La fea pobreza del Barrio Chino tenía patina de historia. No se parecía en nada a la fea pobreza prefabricada por especuladores prefabricados prefabricadotes de barrios prefabricados. Es preferible que la pobreza sea sórdida y no mediocre ${ }^{37}$. Carvalho, cada vez más angustiado por los cambios, simboliza «the relationship between the human mind and the urban environment, and the psychological consequences upon the individual when buildings, public spaces and even entire areas are removed or undergo profound physical changes ${ }^{38}$. Sitios como los alrededores de la Plaça Pedró que caen en el olvido y que le traen, recuerdos de «los terrados de la posguerra, cuando la escasa alimentación les empujaba hacia el sol, como si fueran plantas pobres en busca del único alimento gratuito. Y bajo el sol se construía una vida paralela a la de la calle, liberada incluso de los miedos heredados de la guerra o de los nuevos miedos impuestos por la miseria histórica del franquismo» ${ }^{39}$. Mientras Barcelona se prepara para reinventarse a sí misma y convertirse en una ciudad moderna y cosmopolita, Carvalho, desolado, opta por «encerrarse en su casa de Vallvidriera, puertas y ventanas selladas, incluso ranuras y rendijas, con cinta aislante ${ }^{40}$ para evitar cualquier contagio de ese «ejercicio de sadismo implacable para destruir incluso los cementerios de su memoria, el espacio físico donde podrían residir los protagonistas de sus recuerdos» ${ }^{41}$. La ciudad se convierte en un elemento profundamente alienante que da «ganas de llorar porque sabía que no podía volver a casa, que nunca volvería a casa y que además era imprecisa la casa a la que no se podía

\footnotetext{
${ }^{35}$ M. Vázquez Montalbán (1989), p. 101-02. El propio escritor expresa ideas similares en Diàlegs, p. 55.

${ }^{36}$ G. Morán (1991), p. 16.

${ }^{37}$ M. Vázquez Montalbán (1979), p. 179.

${ }^{38}$ C. Wells (2008), p. 280.

${ }^{39}$ M. Vázquez Montalbán (1987b), pp. 12-3.

${ }^{40}$ M. Vázquez Montalbán (1993), p. 12.

${ }^{41}$ M. Vázquez Montalbán (1993), p. 132.
} 
volver» ${ }^{42}$ Tras treinta años dando voz a los desprotegidos de Barcelona, la ciudad que amaba se había transformado hasta lo irreconocible y el personaje se hace eco de la afirmación de su creador de nos encaminamos hacia un «universalismo [que] no aporta valor de tolerancia o de recepción alguna. Llega con su propio dogma. El supermercado no quiere productos locales, enlata una cultura capitalista de exportación que todo el mundo va a sufrir» ${ }^{43}$ por lo que a Pepe Carvalho no le queda más remedio que irse de Barcelona.

Aunque algunos títulos de la colección habían llevado al detective fuera de Barcelona, como es el caso de Ámsterdam en Tatuaje ${ }^{44}$, Madrid en Asesinato en el comité central ${ }^{45}$, Tailandia en Los pájaros de Bangkok ${ }^{46}$ y Argentina en Quinteto de Buenos Aires ${ }^{47}$, su desesperación nunca había resultado tan patente como en los dos volúmenes de Milenio $^{48}$, en los que traslada sus pesquisas a Afganistán, la India, Tailandia, Australia, Chile y Argentina. Balibrea argumenta que «los treinta y seis años que separan el primer libro de Vázquez Montalbán del momento presente [...] conforman un período histórico que tanto a nivel nacional como global ha sido de transición y, por tanto, de crisis» ${ }^{49}$ y quizás sea ésta última la palabra que mejor define la Barcelona de Carvalho: una ciudad en crisis, no tanto económica, sino de valores, de memoria histórica y social ante la cual, al final, acaba rendido y sin esperanza, como ocurre en El hombre de mi vida ${ }^{50}$.

\section{La Barcelona de Eduardo Mendoza}

Para muchos críticos, La verdad sobre el caso Savolta ${ }^{51}$ introduce la novela negra en España dado su «tono irónico y trágicamente desesperanzado, por la acusación sin paliativos del poder político, policial y económico... el punto de vista del antihéroe y del marginado (Javier Miranda y Nemesio Cabra), al igual que por la descripción realista documental de los medioambiente bajos y delictivos $\rangle^{52}$. Coinciden también en la semejanza entre la situación socio-económica de los años de la transición en España y la sociedad de crisis en los Estados Unidos durante los años veinte y treinta. Ambas sociedades producen la novela negra ya que la situación de inestabilidad da lugar a una reacción literaria que refleja «de una

\footnotetext{
${ }^{42}$ M. Vázquez Montalbán (2000), p. 45.

${ }^{43}$ M. Vázquez Montalbán (1998), p. 155-6.

${ }^{44}$ M. Vázquez Montalbán (1974)

${ }^{45}$ M. Vázquez Montalbán (1981)

${ }^{46}$ M. Vázquez Montalbán (1983)

${ }^{47}$ M. Vázquez Montalbán (1997)

${ }^{48}$ M. Vázquez Montalbán (2004 a, 2004c)

${ }^{49}$ M. P. Balibrea (1999), p. 9.

${ }^{50}$ M. Vázquez Montalbán (2004b).

${ }^{51}$ E. Mendoza (1975)

${ }^{52}$ J. F. Colmeiro (1994), p. 200.
} 
manera crítica las características de esa realidad cotidiana ${ }^{53}$. Mendoza comparte con Vázquez Montalbán el interés por mostrar cómo el desarrollo de la ciudad moldea la conciencia de sus habitantes. Como argumenta el geógrafo y urbanista David Harvey, todo proceso de urbanización está relacionado con el desarrollo del capitalismo que allí se da en un constante movimiento, y tanto el proceso de la urbanización del espacio como el de urbanización de la conciencia y de la política, no son sino parte de lo mismo, transformándose el uno al otro. El espacio urbano es «a metaphor for a site or container of power ${ }^{54}$ que nos revela tanto el dinamismo del proceso urbanístico, como sus tensiones internas al tiempo que el significado de la evolución del capital, por lo que nos puede ayudar a comprender «the dilemmas and confusions that the urban experience produces for political and intellectual consciousness ${ }^{55}$. Mendoza ofrece una fotografía de la conciencia urbana con la que explicar la situación de Barcelona en el momento en que escribió la novela, pero usando sucesos y personajes del pasado, -reales o ficticios-, ya que, afirma uno de sus protagonistas, «siempre seremos lo que ya fuimos» ${ }^{56}$. Como si de un historiador con una agenda programada se tratase, escoge enfatizar aquellos eventos del pasado más relacionados con lo que está ocurriendo ahora ${ }^{57}$.

Lo primero que llama la atención en La verdad sobre el caso Savolta es que la verdad es, cuando menos, difícil de colegir. La novela comienza en un tribunal de New York en 1927 cuando el protagonista, Javier Miranda, testifica en un caso relacionado con el seguro de vida de su ex-jefe Paul-André Lepprince, fallecido en el incendio de una fábrica en Barcelona en 1919. La estructura fragmentada de la novela, llena de comentarios en primera persona y de un narrador omnisciente, cartas, recortes de periódico, documentos del tribunal, etc, hacen de la búsqueda de la verdad una misión casi imposible, si bien proporciona un caleidoscopio de aquella tumultuosa Barcelona, donde los más poderosos disfrutaban del lujo mientras los trabajadores apenas podían subsistir. De los más de treinta personajes que pueblan la novela, Javier Miranda, Paul-André Lepprince y María Coral son los que mejor retratan aquella urbe en crisis donde triunfa el individualismo. Miranda, natural de Valladolid, se mudó a Barcelona en 1917. Su primer trabajo, en las oficinas del abogado Cortabanyes, le permitió llevar una vida más que modesta. En aquel año conocería a otro inmigrante, Lepprince, que asume el control de la fábrica Savolta al poco tiempo. Cuando éste le pide ayuda, Miranda no deja pasar la oportunidad de ganarse un dinero extra sin escrúpulo alguno. No en vano, tras una primera actitud confusa y dubitativa, Javier no tarda en admitir que «lo que buscaba

\footnotetext{
${ }^{53}$ J. F. Colmeiro (1994), p. 211.

${ }^{54}$ D. Harvey (1989), p. 213.

${ }^{55}$ D. Harvey (1989), p. 198.

${ }^{56}$ E. Mendoza (1979), p. 124

${ }^{57}$ M. L. Gazarian Gautier (1991), p. 204.
} 
era el éxito a cualquier precio» ${ }^{58}$. Entre las oportunidades que va aceptando está el casarse con María Coral, la amante de su jefe quien, tras haberlo meditado, «Declaró haberse casado conmigo por interés, sin que mediase sentimiento alguno en su decisión. Tenía la conciencia tranquila porque suponía que yo no era víctima de un engaño y que también la había desposado como medio de obtener algún provecho» ${ }^{59}$. Dejando de lado cualquier valoración moral, la posibilidad de salir de la miseria les hace huir hacia delante. Ni siquiera cuando Miranda se compra una casa de clase media alta en el Eixample ésta le pertenece realmente, pues Lepprince entra y sale a voluntad, recordándole «qué sencillo es todo cuando se tiene dinero y poder ${ }^{60}$. En el polo opuesto, los demás trabajadores, incapaces de ponerse de acuerdo y de unir estrategias y objetivos ante la opresión de los empresarios, únicamente logran que la ciudad se asemeje a un campo de batalla. Tal y como señalan los informes del juez Davidson: «se produjeron en Barcelona ochenta y siete atentados de los llamados «sociales», cuyo balance de víctimas es el siguiente: patrones muertos, 4; heridos, 9; obreros y encargados muertos, 11; heridos; 43. Esto sin contar los daños materiales causados por los numerosos incendios y explosiones dinamiteras $\rangle^{61}$. Se trata de una larga y cruenta lucha de clases que provocaba convulsiones cada vez más trágicas y que se estaba desviando del objetivo inicial, pues «todos los combatientes (obreros y patrones, políticos, terroristas y conspiradores) habían perdido el sentido de la proporción, olvidado los motivos y renunciado a los logros. Más unidos por el antagonismo y la angustia que separados por las diferencias ideológicas, los españoles descendíamos en confusa turbamulta una escala de Jacob invertida» ${ }^{62}$.

Este desesperanzador paisaje lo conocemos principalmente gracias a dos personajes: un utópico anarquista, Pajarito de Soto, y un loco, Nemesio Cabra. Pajarito publica artículos incendiarios denunciando la explotación de la oligarquía industrial catalana, a la que califica de «bestia rampante» ${ }^{63}$, lo que le conducirá a una muerte trágica disfrazada de accidente. En esta inquietante fotografía aparece Nemesio Cabra, antecedente del protagonista sin nombre de varias novelas posteriores. Confidente de la policía y de cualquiera que pague sus servicios, Cabra es un pícaro de los bajos fondos cuya motivación reside en las necesidades del sustento. Presenta, sin embargo, un rasgo que lo diferencia del típico pícaro: afirma ser «poseedor de grandes verdades que me han sido reveladas en mi sueño por nube o llama o no sé qué (por la gracia divina) $»^{64}$. Alejándose de la mirada desasosegada

\footnotetext{
${ }^{58}$ E. Mendoza (1975), p. 52.

${ }^{59}$ E. Mendoza (1975), p. 308-09.

${ }^{60}$ E. Mendoza (1975), p. 346.

${ }^{61}$ E. Mendoza (1975), p. 168-9.

${ }^{62}$ E. Mendoza (1975), p. 216-17.

${ }^{63}$ E. Mendoza (1975), p. 78.

${ }^{64}$ E. Mendoza (1975), p. 117.
} 
de Carvalho, Mendoza opta por la ironía de alguien que parece no estar cuerdo. Aunque posee una de las claves del caso, sus propias declaraciones nos hacen dudar de él: «No soy un criminal ni un loco como pretenden sólo soy una víctima de las añagazas del Maligno ${ }^{65}$. Rechazado por el comisario, maltratado por el tabernero e insultado por los miembros de la célula anarquista, supone una nueva manera de ver la ciudad.

Ante la falta de credibilidad de los personajes, movidos por la ambición, por la utopía o por la locura, lo mejor de Mendoza es su descripción de la intriga urbana, la cual se desarrolla en tres espacios urbanos claramente delimitados. El de los ricos se encuentra alejado de todo el ambiente de batalla campal, como la lujosa mansión de Savolta en el exclusivo barrio de Sarrià, «enclavada en [...] un montículo que domina Barcelona y el mar. Las casas eran del tipo llamado «torre», a saber: viviendas de dos o una planta rodeadas de jardín» ${ }^{66}$. Un arribista como Lepprince pasará de vivir en una casa en los «barrios pacíficos y virtuosos de la clase media» ${ }^{67}$ a mudarse a la de su difunto suegro: Savolta. Espacios con una realidad refinada de lujo y espejos que devuelven «destellos al recibir los rayos de un sol primaveral en su cenit [...] la cristalera corrida que daba sobre un amplio porche terminado en una escalera de barandal de piedra que descendía hasta una ondulante explanada de césped tierno» ${ }^{68}$ que nada tienen que ver con zonas como el Barri Xino, un «laberinto de callejones, ruinas y desperdicios» ${ }^{69}$ donde «las aceras estaban atiborradas de gentes harapientas de torva catadura, que buscaban en aquel ambiente de bajeza y corrupción el consuelo fugaz a sus desgracias cotidianas. Los borrachos cantaban y serpenteaban, las prostitutas se ofrecían impúdicamente desde los soportales, bajo las trémulas farolas de gas verdoso» ${ }^{70}$. Lugares como la mísera pensión donde vivía María Coral antes de casarse y que ayuda a comprender que estén dispuestos a cualquier cosa por salir de sitios como la «casa de habitaciones que [...] hacía las veces de casa de citas. La entrada era estrecha y oscura. [...] Subí los desgastados peldaños alumbrándome ocasionalmente con una cerilla y a tientas. La lobreguez del entorno, lejos de deprimirme, me animó, pues evidenciaba que María Coral no disfrutaba de una posición que le autorizase a despreciarme» ${ }^{71}$. Aún peor estaban los trabajadores de Savolta, en chabolas en el área que va desde Barcelona hasta la fábrica, en el Hospitalet: «Los suburbios quietos esperaban y

${ }^{65}$ E. Mendoza (1975), p. 117.

${ }^{66}$ E. Mendoza (1975), p. 108.

${ }^{67}$ E. Mendoza (1975), p. 73.

${ }^{68}$ E. Mendoza (1975), p. 130.

${ }^{69}$ E. Mendoza (1975), p. 187.

${ }^{70}$ E. Mendoza (1975), p. 129.

${ }^{71}$ E. Mendoza (1975), p. 2099. 
callaban, uncidos a la ciudad, como la hiedra al muro» ${ }^{72}$. Para Mcneill, en 1975 estos mismos espacios aún mostraban el mismo tipo de segregación que en $1918^{73}$.

Esta ciudad de escasos modelos positivos tampoco ofrece una imagen halagüeña de la policía. El comisario Vázquez no era persona que causara buena impresión por «su mirada displicente y su media sonrisa irónica y aquella lentitud profesional que ponía en sus palabras y sus movimientos, tendente sin duda a exasperar e inquietar y a provocar una súbita e irrefrenable confesión de culpabilidad en el oyente. [...] La primera vez que le vi lo juzgué de una pedantería infantil, casi patética» ${ }^{74}$. Pese a su intención de descubrir la verdad, este comisario con nombre de escritor comete varios errores, obviando la declaración de Pajarito, lo cual le acaba costando la vida a éste, y menospreciando a Cabra, a quien considera «un verdadero desecho social ${ }^{75}$. Cuando finalmente les da crédito, interfiere con los intereses de sus superiores, que primero le transfieren a Tetuán y luego a Guinea. Al regresar a Barcelona, «abandonó el cuerpo de Policía en 1920, es decir, según mis cálculos, cuando sus investigaciones debían estar llegando al final. Algo misterioso hay en ello. Pero nunca se sabrá, porque hace pocos meses fue muerto por alguien relacionado con el caso» ${ }^{76}$.

El misterio de la cripta embrujada muestra la Barcelona de finales de los setenta a través de los ojos de un ser marginado que nos recuerda a Cabra, un detective sin nombre que es liberado temporalmente del manicomio para ayudar al comisario Flores en su investigación del caso de una niña desaparecida. El protagonista inicia sus pesquisas en el Barri Xino y descubre los negocios sucios del industrial Preaplana, recordándonos la afirmación de Carvalho acerca de donde viven sus clientes y sus víctimas. Gracias a este peculiar detective alejado de la típica imagen hard-boiled de los protagonistas de la novela negra norteamericana, Mendoza sigue la tónica de Vázquez Montalbán de preferir la crítica social al tiempo que proporciona misterio, aventuras, búsqueda de una solución paso por paso y resolución del caso, sin seguir el método del whodunnit estadounidense. La gran diferencia entre ellos reside en que mientras el detective de Vázquez Montalbán es un gran gourmet que posee un tremendo sentido de justicia social, el detective de Mendoza es un protagonista sin nombre, extraño y marginado, acuciado por la paranoia y por una peculiar adicción: la Pepsi-Cola. Su falta de identidad no hace sino reforzar su carácter picaresco: «Soy, en efecto, fui, más bien, y no de forma alternativa sino cumulativamente, un loco, un malvado y una persona de instrucción y cultura deficientes... no tuve otra escuela que la calle ni otro

\footnotetext{
${ }^{72}$ E. Mendoza (1975), p. 77-8.

${ }^{73}$ D. McNeill (1999)

${ }^{74}$ E. Mendoza (1975), p. 42.

${ }^{75}$ E. Mendoza (1975), p. 418.

${ }^{76}$ E. Mendoza (1975), p. 42.
} 
maestro que las malas compañías de que supe rodearme ${ }^{77}$. Pese a todo, posee una sorprendente capacidad para la lógica, la deducción y la dicción, como en este retrato que ofrece de sí mismo: «las bellas palabras, engarzadas en el dije de una correcta sintaxis, pueden embelesarme unos instantes, desenfocar mi perspectiva, enturbiar mi visión de la realidad. Pero estos efectos no son duraderos; mi instinto de conservación es demasiado agudo, mi apego a la vida, demasiado firme, mi experiencia demasiado amarga en estas lides ${ }^{78}$. Por instinto evita reestablecer el orden social o seguir un código de conducta superior a lo Marlowe, pues afirma que «Apelaría al amor a la verdad y a la justicia y a otros valores absolutos si éstos fueran mi brújula, pero no sé mentir cuando se trata de principios. Si supiera, no sería una escoria como he sido toda mi vida ${ }^{79}$. Al presentar los vicios de la ciudad por medio de alguien que se autodenomina escoria, Mendoza refuerza la imagen de insalubridad de la misma, en la que ni la policía sale bien parada. El comisario Flores, quien le rompiera un diente en un interrogatorio, es una persona cuyas «facciones algo bastas no tenían otra característica digna de mención» ${ }^{80}$ y sus subalternos se caracterizan por su ignorancia, su incapacidad para manejar situaciones complejas, y sus modos groseros: «Identificarse, cabrones [...] Hurra, inspector, los haimos trincao con la mano en la massa $\rangle^{81}$. Así no es de extrañar que, para no inculpar a Preaplana, encubran las evidencias de sus negocios ilegales y vuelvan a meter al protagonista en el manicomio.

Como la ciudad que veía Carvalho desde casa, esta Barcelona es tan sucia que a sus calles «sólo les falta techo para ser cloaca» ${ }^{82}$, como ocurre con la pensión en que se alojó, que «era una pocilga y olía a meados. Las sábanas estaban tan sucias que hube de despegarlas tironeando... el cuarto de baño comunal parecía una piscina, el water y el lavabo estaban embozados ${ }^{83}$. Los pisos particulares tampoco se escapan de este ambiente, pues están habitados por bichos y roedores: «Nos detuvimos frente a un inmueble renegrido y arruinado de cuyo portal salió una lagartija que mordisqueaba un escarabajo mientras se debatía en las fauces de un ratón que corría perseguido por un gato» ${ }^{84}$, curiosa simbología de la escala social. Los menos privilegiados, aunque se trate de un dentista, viven en condiciones deplorables, como un edificio en el barrio del Ensanche que se caracteriza por «su fachada gris, maciza, vulgar y un poco triste [con un ascensor que parece] un ataúd

\footnotetext{
${ }^{77}$ E. Mendoza (1979), p. 15.

${ }^{78}$ E. Mendoza (1979), p. 15.

${ }^{79}$ E. Mendoza (1979), p. 77.

${ }^{80}$ E. Mendoza (1979), p. 11.

${ }^{81}$ E. Mendoza (1979), p. 49.

${ }^{82}$ E. Mendoza (1979), p. 47.

${ }^{83}$ E. Mendoza (1979), p. 37.

${ }^{84}$ E. Mendoza (1979), p. 47.
} 
$\mathrm{y}$ un recibidor pobremente iluminado por una bombilla de bajo voltaje, [y un] pasillo estrecho y oscuro, y otros muebles sencillos» ${ }^{85}$.

Pese a los intentos de dar una imagen de una ciudad que ha progresado, esta Barcelona no da lugar a la complacencia, pues incluso el sistema educativo, fuente de la sociedad futura, deja que desear. Presenta una imagen de libertinaje, de concupiscencia, de falta de valores y de conocimientos que no parece que vaya a servir a los jóvenes, añorando incluso la enseñanza de «Antes, en mis tiempos, quiero decir, la enseñanza era otra cosa. Los chavales se lo pasaban bien con el erotismo primitivo de la historia sagrada y la fábula edulcorada de nuestras gestas imperiales. Ahora, en cambio, todo son teorías de conjuntos, perogrulladas lingüísticas y una desestimulante e improbable educación sexual» ${ }^{86}$. La educación tampoco parece brillar entre las mujeres quienes, como en la serie Carvalho, desempeñan papeles secundarios que contribuyen al desarrollo de la historia y que, a lo sumo, posibilitan que se desentrañe el misterio. Mercedes Negrer, por ejemplo, gusta de las novelas populares y las revistas del corazón como Hola y Diez Minutos, de donde extrae sus principales ideas. A ojos del dentista, a estas mujeres «sus madres les llenaron la cabeza de fantasía, todas se creen que son Grace Kelley» ${ }^{87}$, buscando huir de la mediocridad pero sin poner los medios para ello.

Con Barcelona preparándose para el partido inaugural del Mundial de Fútbol de 1982 en El laberinto de las aceitunas, el protagonista se encuentra con una actriz con el nombre artístico de Suzanna Trash, apellido que significa basura en inglés, y con su vecino, el historiador Plutarquete, recordándonos al historiador y filósofo griego. Esta curiosa triada de locura, mala actuación y filosofía revelará que, lo que parecía una conspiración para provocar un accidente atómico a nivel mundial, era un simple caso de soborno para intentar recalificar suelo y hacer que las tierras de un convento pasen a ser zona turística; un caso más de pelotazo urbanístico. En esta ocasión, al detective sin nombre, escogido porque su aislamiento social le hace «un intermediario digno de confianza que... no tenga contacto ninguno con medios de difusión, círculos políticos, corrillos bursátiles, cónclaves eclesiásticos ni salas de banderas ${ }^{88}$, se le une una mujer que, aún no siendo una figura muy positiva, supone una pequeña evolución tanto por su papel activo como por su actitud menos estereotipada. Emilia, Suzanna Trash, es una mujer que «Aun descalza era tan alta como yo, cuadrada de hombros y un tanto rectilínea, al menos para mi gusto, de formas. Sus gestos eran rápidos, nerviosos y en general innecesarios, y su mirada tenía esa mezcla de movilidad y concentración propia de los boxeadores» ${ }^{89}$, lejos de las mencionadas lectoras de las revistas del corazón y, como persona con iniciativa

${ }^{85}$ E. Mendoza (1979), p. 137-8.

${ }^{86}$ E. Mendoza (1979), p. 87.

${ }^{87}$ E. Mendoza (1979), p. 145.

${ }^{88}$ E. Mendoza (1982), p. 21.

${ }^{89}$ E. Mendoza (1982), p. 67. 
propia, «se había desprendido de sus ropas... se me vino encima, me estrechó entre sus brazos... Y me convirtió en sujeto pasivo al principio, activo luego y ruidoso siempre de actos que no describiré» ${ }^{90}$. Pese a todo, sus aspiraciones por llegar a triunfar como actriz no tendrán éxito.

Aunque la ciudad se prepara para un acontecimiento mundial, la policía continúa con sus viejos defectos. Del comisario destaca su «aliñado vestir, gesto viril y labia fácil, si bien la guadaña impía del tiempo había restado donaire a su fina estampa, que no empaque, abotargando su faz, desertificando su cráneo, cariando sus molares, acreciendo michelines a su cintura y activando sus glándulas sebáceas en todo clima, lugar y circunstancias» ${ }^{91}$ provocando una sensación desagradable que se acentúa con frases del tipo: «Ni una maña o te dejo la cara más aplastada que el producto interior bruto ${ }^{92}$; un agente de la ley que deja tanto que desear como los barrios más pobres.

La hermana del detective, Cándida, vive en un lugar tan feo y ruinoso que «La fosa común del Cementerio Viejo debía de ser más acogedora que el edificio en ruinas donde moraba mi hermana $\rangle^{93}$, un sitio tan pequeño que en él sólo cabe una cama y un viejo tocador; mientras que el actor Muscle Power vive en la calle del Gaseoducto, donde las «ratas muertas festoneaban la calzada» ${ }^{94}$. Emilia, a su vez, vivía en un pueblo cercano donde las casas bajas típicas de los pueblos estaban siendo derruidas, con la consiguiente imagen de zona de guerra tan recurrente en Mendoza. Por la parte pudiente, la empresa olivarera especuladora ocupa un moderno edificio de cuatro pisos cuya fachada está «recubierta de vidrios reflectantes y ornamentada con protuberancias de acero inoxidable» ${ }^{95}$, símbolo a la vez de modernidad y de corrupción. Mendoza, gracias a la imagen de «España cutre» con calles sucias, pensiones pestilentes y repulsivas, investigadores incompetentes, oligarquía corrupta y un sistema educativo ineficaz, sin caer en el pesimismo de Vázquez Montalbán, provoca a la vez una sonrisa y una sensación de desánimo ${ }^{96}$ para hacernos reflexionar.

Cada vez que Mendoza retrata Barcelona, ya sea a modo de novela negra o no, lo hace siempre presentando un lugar de luces y de sombras con el que el autor mantiene una relación de amor-odio. Amor como el que puede verse en la representación de la colonia veraniega donde las familias de clase alta de Una comedia ligera pasan el verano, el Mansou, donde: «Los rayos del sol caían perpendicularmente sobre la arena y el aire parecía embebido de una claridad

\footnotetext{
${ }^{90}$ E. Mendoza (1982), p. 166-67.

${ }^{91}$ E. Mendoza (1982), p. 12.

${ }^{92}$ E. Mendoza (1982), p. 13.

${ }^{93}$ E. Mendoza (1982), p. 50.

${ }^{94}$ E. Mendoza (1982), p. 54.

${ }^{95}$ E. Mendoza (1982), p. 180.

${ }^{96}$ P. Hart (1987), p. 104.
} 
lechosa. Los gritos de los niños y el graznido de las gaviotas cubrían el ruido de las olas ${ }^{97}$, mostrado como refugio de aquella Barcelona que recibe al viandante con «un olor ocre y espeso [como si fuera] un gas letal [si bien es] el tufo inofensivo de varios siglos de orines y fritanga $\rangle^{98}$. Siempre presentando la dualidad de amor-odio que mantiene con su ciudad ${ }^{99}$, Mendoza gusta de contrastes entre sitios como el café La Luna, frecuentado por jóvenes bohemios, y otros como la asimétrica Taberna de Manuel, «una pieza irregular, angosta y profunda, de techo bajo» y de peor clientela, aunque, a su juicio, más representativa de la sociedad: «vulgar y zafio, pero auténtico» ${ }^{100}$.

Sus figuras femeninas continúan su lenta evolución y desempeñan un papel más importante. Cabe mencionar a Marichuli Mercadal, una mujer atractiva perteneciente a la burguesía catalana, casada con un eminente cirujano. De naturaleza sensual, fiel al estereotipo de las mujeres pelirrojas, disfruta de sus amoríos con Prullás, lo cual compagina con su sentimiento de culpa posterior; de nuevo los contrastes. Al igual que el detective sin nombre, tampoco tiene reparo en reconocer su maldad: «no intento ocupar ningún lugar en tu corazón ni en tu vida. Soy mala, ¿entiendes? Encuentro placer en el mal. Soy desvergonzada y perversa» ${ }^{101}$ y gusta de seguir el modelo de Bette Davis en Para ella no había otra ley que su capricho. Como personaje estereotípico, le corroe el sentimiento de culpa y accede a someterse a una lobotomía en este mundo que está siendo investigado, irónicamente, por un loco. Los estereotipos continúan con Lilí Villalba, una joven actriz de clase baja que se esfuerza en medrar a toda costa y busca la protección del empresario Prullás. Su falta de capacidad para el teatro le impedirá conseguir sus objetivos. Pese a todo, no debemos olvidar que el uso de los estereotipos es parte de la técnica paródica del escritor barcelonés.

La relación entre la ciudad y el autor carece de todo reposo. Es un canto agridulce, satírico, donde el mito pierde sus perfiles y se convierte en irrisión, en el leguaje de un loco, aunque sin llegar al desánimo de Carvalho. Si la Barcelona del detective sin nombre tiene mucho en común con la que Vázquez Montalbán describe en Desde los tejados, la ciudad que Mendoza dibuja en La ciudad de los prodigios guarda relación con la de Sabotaje Olímpico, El delantero centro fue asesinado al atardecer o Los mares del Sur. Carvalho recorre las calles de la ciudad y se mantiene fiel a su compromiso de dar voz al que no la tiene, echando mano de la memoria del pasado, al tiempo que busca la justicia. Los personajes de Mendoza, en cambio, o se unen al poderoso como hacen Javier Miranda o María Coral, pues no ven otra opción para salir de la miseria, o se convierten en poderosos sin

${ }^{97}$ E. Mendoza (1996), p. 35.

${ }^{98}$ E. Mendoza (1996), p. 190.

99 C. Sarrias (1986)

${ }^{100}$ E. Mendoza (1996), p. 142-3.

${ }^{101}$ E. Mendoza (1996), p. 68. 
escrúpulos como Onofre Bouvila, o sencillamente son unos pícaros locos carentes de nombre; tal vez la única manera de soportar una realidad que deja «el ánimo abatido y creí que hasta la sombra me pesaba. Me detuve en una cervecería y bebía una cerveza mientras meditaba en las palabras de la Doloretas. Su historia era la historia de las gentes de Barcelona» ${ }^{102}$.

\section{La Barcelona de Carmen Riera}

Mientras ambos escritores presentan, con desánimo o con ironía, la vida de los más desfavorecidos como la de la verdadera gente de Barcelona, Carme Riera opta por centrar su primera novela negra en el campus de la Universitat de Barcelona y sus alrededores. Inspirándose en diversos modelos literarios como Donna Leon, Nansa Laarson, Mari Jungstedt o los españoles Andreu Martín, Alicia GiménezBartlett o Francisco González Ledesma, Riera muestra un hondo conocimiento de la ortodoxia del género y un gran control de sus normas. Partiendo de una doble base real, a la desaparición en 2007 de un estudiante ${ }^{103}$, se le suma el hecho de que una joven rumana que ayudaba a la autora en las tareas domésticas, muy lista y que quería estudiar una carrera, también desapareciera un día cuando unos familiares se la llevaron a su país. Natura quasi morta comienza con una imagen de una universidad atractiva, agradable, moderna, un lugar amplio, lleno de vida, y con 230 hectáreas de espacios verdes, «un Campus d'Excel-lència únic a Catalunya, compta amb 57 departaments i una potent activitat investigadora. Moltes ciutats del nostre país no estan tan poblades ni per descomptat tenen un nivell neuronal tan alt ${ }^{104}$. Tales excelencias investigadoras y neuronales pronto dan paso a las miserias de la condición humana, comenzando por los ocupas anti-Bolonia y por la noticia de la desaparición de Constantinu Iliescu. Pese a las bondades del anuncio inicial, encontramos un duro paisaje urbano donde la naturaleza ha sido sometida a la tiranía humana, como recordaba el profesor Bellpuig, «Havia vist com s' aixecaven els primers edificis d' aquella nova universitat que havia de ser tan distinta de la resta, en uns terennys plens de cucs negres on encara pasturaven els bens. La diferència amb el mastodontic campus actual era enorme, però encara ho eren més els ideals dels qui la fundaren respecte de les idees dels d' ara» ${ }^{105}$. Estos ideales parecen haber sufrido los mismos cambios que apuntara Harvey, estableciendo una similitud entre el paisaje urbano y la conciencia de quienes lo habitan. Junto a la universidad, lo que antes había sido un bosque ha quedado reducido a un pequeño reducto destinado a vertedero ilegal en el que, significativamente, se encontrará el

\footnotetext{
102 E. Mendoza (1986), p. 391.

103 Romain Lannuzel, era un estudiante Erasmus que se estaba mudando para estar más cerca de Bellaterra cuando desapareció. Su caso sigue vivo en Internet, aunque las autoridades aún no saben nada,

${ }^{104}$ C. Riera (2011), p. 11

${ }^{105}$ C. Riera (2011), p. 22.
} 
cuerpo de Laura Cremona, una de los tres muertos de la novela. Víctima del progreso descontrolado, Riera plantea un simbólico nexo entre los asesinos de personas y los que han llenado el lugar de «-electrodomèstics rovellats, sacs de runa, plàstics bruts- que, amb una tossuderia a prova de plugues i tempestes, seguien resistint la intempèrie dels anys. Feia temps que uns assassins de paisatges havien fet servir del llo d' abocador» ${ }^{106}$. Lo único que se salvaba por allí eran, casi en el borde con la autopista, unas barracas de pagesos que en unos pocos metros cultivaban «tomaqueres anèmiques o bledes escarransides, segons l' època del any» ${ }^{107}$, planteándonos el interrogante de qué hemos hecho con nuestro sistema de vida tradicional. La respuesta de Riera no es el desánimo o la ironía, sino el enfrentamiento. Cuando los mossos de escuadra están investigando la zona, son atacados por un pagès que les orina encima $\mathrm{y}$, al ver éstos no pueden usar sus pistolas por lo ridículo de la agresión, les lanza una piedra. El pagès, que dice ser el príncipe de Aquitania y dueño de «el Corte Inglés de Sabadell i em penso que tambè del de la Diagonal de les Barcelones, vicepresident del Barça [y con] immunitat parlamentaria, jo, i no em podeu detenir ni atacar» ${ }^{108}$, no sólo proporciona una nota de humor, sino que nos remite a las consecuencias del discurso del presidente del FC Barcelona de Vázquez Montalván, o a los comentarios del detective sin nombre de Mendoza, al tiempo que recuerda al lector los constantes casos de corrupción en que se ven envueltos políticos que, por su condición, están libres de ser perseguidos por la justicia. El individuo resultó venir de familia bien y haber sido abogado de profesión antes de volverse esquizofrénico. La sonrisa inicial se nos puede quedar helada pues, al igual que a Mendoza, a Riera tampoco le gusta hacia dónde se dirige la sociedad: «A mí me interesa la literatura que muestre no sólo el entorno, sino que además intente analizar la condición del ser humano y, en este sentido, soy escritora, supongo, porque tampoco me gusta el mundo en el que vivo» ${ }^{109}$. De esta manera, Riera no sólo continúa con su costumbre de mostrar cómo funcionan los entresijos del poder, el entramado de abusos, clientelismos y corrupciones que se esconden detrás de supuestos ideales y de discursos oficiales por medio de una voz femenina ${ }^{110}$, sino que nos plantea la crisis de valores de la sociedad contemporánea incluso allí donde se supone que éstos perviven: en la universidad.

Los primeros pasos de la investigación sobre la desaparición de Iliescu los da la encargada de los estudiantes Erasmus, la profesora Rosa Casasaies, quien primero llama a la pensión del Raval que indica en su ficha, donde el chico sólo había estado tres días para, acto seguido, llamar a la dirección que tenían de éste en Rumanía,

\footnotetext{
${ }^{106}$ C. Riera (2011), p. 118.

${ }^{107}$ C. Riera (2011), p. 118.

${ }^{108}$ C. Riera (2011), p. 120.

${ }^{109}$ P. Farrington (2000), p. 82.

${ }^{110}$ E. Ramón (2006), p. 6.
} 
donde tampoco saben nada. Sus intentos de conseguir alguna información por parte de la universidad de Bucarest tampoco obtuvieron mejores frutos. Cuando la investigación pasa al ámbito policial, a cargo de la subinspectora Manuela Vázquez, la profesora continuará ayudando de manera activa. De esta manera, la narración se adentra tanto en el mundo policial y político, como en el mundo de los académicos y el de sus dicentes universitarios, dos mundos que, irónicamente, padecen falta de comunicación. El primer sospechoso, Marcel Bru, resulta ser amigo de la segunda estudiante desaparecida. Su domicilio familiar figura en Vilanova i la Geltrú, ciudad marítima en la provincia de Barcelona y casi equidistante de Tarragona (46 kms) y de Barcelona (44 kms), mientras que su domicilio en la ciudad condal se halla en el barrio de Sants, uno de los más comerciales y mejor comunicados. Los Mossos, obsesionados por distanciarse de la policía franquista, a la hora de ir a buscarlo querían evitar aparecer con las primeras horas de la mañana, en medio del silencio y de la oscuridad, como hacían con los disidentes políticos antes de la democracia. Pese a su preocupación, por cuestiones prácticas tuvieron que ir a las siete de la mañana, aunque la realidad ahora es muy diferente. Donde antes había fábricas ahora hay nuevos proyectos urbanísticos, negocios y ruidos: «Els bars, supermercats, fruiteries i la resta de botigues de queuviures, els més matiners entre els comerços [...] les furgonetes i els camions de repartiment que venien de Mercabarna amd provisions per descarregar obstaculitzaven el pas, no s' estaven de tocar el clàxon, sense preocupar-se per si encara hi havia veïns que dormien» ${ }^{111}$, proporcionando una imagen de gente trabajadora a la que nada le importa el descanso de los demás. En este barrio, alejado de la dignidad de los de Vázquez Montalbán, vive el sospechoso en una vivienda protegida de 1957 con el portal «obert, no hi havia ascensor i l'escala, estreta, empinada i fosca» ${ }^{12}$ que bien puede recordar a las descritas por Mendoza. En el piso en cuestión, las ollas y cazuelas con restos de comida florecida se acumulan en la cocina, los cajones de la mesita de noche del dormitorio acogen restos de porros y preservativos usados y, en el baño «devia fer molt de temps que no s' hi passava ni un trist fregall. La porcellana dels sanitaris tenia un color d'atac de fetge rabiós i sobre el groc hepàtic triomfaven els pèls de les barbes i els cabells des que s'afaitaven i es pentinaven davant del mirall atrotinat que hi havia sobre la pica del lavabo» ${ }^{113}$. Al contrario que con Mendoza, esta falta de higiene no se debe a las condiciones miserables de un proletariado explotado, sino a la dejadez de unos jóvenes a los que no les falta de nada y cuyos padres mantienen fuera del domicilio familiar. Estos universitarios, lejos de representar la posibilidad de un futuro mejor, son percibidos por una vecina como unos «bandarres que vivien de nit i dormien de dia» ${ }^{114}$. Su compañero de piso, hijo

\footnotetext{
${ }^{111}$ C. Riera (2011), p. 80.

112 C. Riera (2011), p. 82.

${ }^{113}$ C. Riera (2011), p. 84.

${ }^{114}$ C. Riera (2011), p. 82.
} 
de abogado y estudiante de derecho, presenta una actitud desafiante ante la policía e, ironizando por un juicio por malos tratos que se está llevando a cabo contra miembros del cuerpo les espeta: «Ep, anem per per parts, què us heu pensat? ja sé com les gasteu. que veniu de les Corts?» ${ }^{115}$. Las malas maneras con que exige ver el mandato judicial para que la policía esté allí evidencian la clara brecha social entre los representantes de la ley y los jóvenes, incluso aquellos que quieren dedicarse a trabajar con la justicia en el futuro. Pese a no ser un interrogatorio, Ràfols se ampara en la ley para no responder a ninguna de las preguntas que le hacen sin estar presente un abogado. Ya en comisaría, Marcel Bru también se muestra desafiante y ni siquiera se digna a contestar si ha entendido sus derechos constitucionales pese a que su actitud la hace parecer aún más sospechoso; un desafío a la norma social y a los representantes de la ley sin parangón en las novelas anteriores.

Lejos de los jóvenes que no podían acceder a un futuro mejor como vemos en Los mares del Sur, o de las miserias que han de soportar los que pululan por La verdad sobre el caso Savolta, éstos no sólo desconocen la cultura del esfuerzo, sino que también desconocen la historia. Los okupas anti Bolonia, que además de ocupar edificios del campus ocasionaron destrozos de mobiliario, robaron ordenadores y atacaron a guardias de seguridad en una supuesta defensa de sus derechos, comparan al equipo rectoral y decanal con Hitler y con Franco, cuando algunos incluso provienen de familias de represaliados, como la decana, «filla de republicans represaliats pel franquisme i antifranquista ella mateixa, li costava d' entendre per quien estrany mecanisme pervers aqulles nois i noies que havien ocupat la Facultat s' obstinaven a no reconèixer la seva trajectoria de lluitadora per la democràcia i les llibertats, i l' assimilaven, sense cap raó, a aquells dos monstres» ${ }^{116}$. Para éstos, tanto policías como docentes son «forces repressores»a los que culpar de la desaparición de Iliescu así como, en última instancia, a «els burguesos capitalistes» ${ }^{117}$, reminiscencia tal vez de un lenguaje que, si bien tiene sentido en las obras de Vázquez Montalbán y de Mendoza, se queda hueco en boca de éstos. Cuando los medios de comunicación dejaron de lado la ocupación para dedicarse a la cobertura de las muertes violentas, Miquel Oliver, el líder de los okupas, les acusa de «tapar la lluita democràtica [y de] oblidar que la Facultat de Lletres estava ocupada en defensa del drets dels estudiants, en defense de les llibertats ${ }^{118}$ ante un grupo de admiradores que no encontraban ninguna incongruencia entre sus afirmaciones y sus acciones violentas.

Entre los que sí van a clase, el panorama tampoco es muy halagüeño. En un trabajo comparativo sobre las obras de Zurbarán y de Flegel, Laura Cremona afirmaba alegremente que «M'agrada més Zurbarán, deia, trobo que Flegel no

\footnotetext{
115 C. Riera (2011), p. 83.

${ }^{116}$ C. Riera (2011), p. 17.

${ }^{117}$ C. Riera (2011), p. 68.

${ }^{118}$ C. Riera (2011), p. 199.
} 
hauria de pintar ni mosques ni mosquits» ${ }^{119}$ para terminar firmando con su nombre en letra bien grande, y dentro de una nube, dejando patente su interés intelectual. Lo que más parece interesarles son las zonas de marcha de la ciudad y, en el transcurso de la investigación, el lector sigue los pasos de Bru y de sus amigos por el Raval, la Zona Hermètica de Sabadell, y de vuelta al Raval. Las descripciones que hace Riera distan mucho de los paisajes urbanos y emocionales de sus colegas masculinos. En un guiño a los ambientes norteamericanos, encontramos la discoteca Global, que recuerda a las películas estadounidenses dado que «Vaig haver de fer cua para entrar, perquè hi havia molta gent $\mathrm{i}$ em vaig quedar amb ell $\mathrm{i}$ els seus amics fins a les sis de la matinada» ${ }^{120}$. Al volver al Raval, tras pasar por el bar Kentucky, nos comenta la curiosidad de que en el bar 23 Robadors, "per entrar-hi s' hagués de tocar un timbre, encara que a dintre no hi hagués res de clandestí»» ${ }^{121}$, otro guiño a las viejas novelas del género al tiempo que al pastiche, pues dentro se escucha música flamenca. Pese a tratarse de uno de los paisajes urbanos más duros de la ciudad, tantas veces retratado, la escritora mallorquina apenas presta atención a su descripción física y opta por dar ligeras pinceladas de estos locales donde igual ofrecen flamenco, jazz o exposiciones de arte, o de las zonas donde abundan los espectáculos sensuales como en la Hermética. Al mencionar Ciutat Badía, la zona de viviendas y de bosque cercana a la universidad, Riera hace referencia a una explosión urbanística que pudiera recordar a la de Los mares del Sur, sólo que en este caso la zona ha mejorado en calidad de vida, bien comunicada, con servicios y muchas zonas verdes, gracias a un potente movimiento asociativo y vecinal.

Las diferencias con los dos escritores también atañen al mundo de los ricos, pues en Riera, ni son hombres ni se dedican a la especulación y a la explotación. Quienes mayor poder adquisitivo disfrutan en esta novela son las dos «madres» de Laura Cremona, Clara Cremona, diseñadora de joyas, y Margaret Hogarth, exparlamentaria en Bruselas, a quienes vemos llorosas y desconsoladas por la muerte de su hija. Riera reconoce la obra de Vázquez Montalbán al tiempo que marca sus distancias y, para ello, aprovecha la figura del cónsul italiano, quien busca una oportunidad para medrar llevándolas a comer al restaurante Hispania, en Arenys de Mar, uno de los mejores de Cataluña. Bracalante, como Carvalho, partía de la hipótesis de que «les sensacions agradables que envien al cervell les papiles gustatives ens poden arribar a treure del cap les penes més amargues», sin embargo, muy a su pesar, el momento de relajación duró mucho menos de lo esperado, por lo que pensó que «el cervell femení, diferent del masculí, no semblava estimulat de la mateixa manera pel plaer que provenia del paladar. en el cas dels homes no dubtava

\footnotetext{
${ }^{119}$ C. Riera (2011), p. 32.

${ }^{120}$ C. Riera (2011), p. 90.

${ }^{121}$ C. Riera (2011), p. 95.
} 
gen de la influència gastronòmica benefactora. Ho havia comprovat de manera directa $\mathrm{amb}$ amics arruïnats, vidus oi abandonats per les seves esposes» ${ }^{122}$, un nuevo guiño a las novelas de su amigo. Tampoco sería común ver en una novela de Carvalho que, en medio del restaurante, una mujer rica «mig plorosa [...] sense importar-li què podríia pensar el seu amfitrió ni les personas que dinaven a les taules de la vora, traqué un ós de peluix de color marró una mica atrotinat i l' abraçà» $^{123}$, el peluche preferido de la desaparecida. En el momento del funeral, lejos del desasosiego pesimista de Carvalho o de la incrédula locura del detective sin nombre, Riera presenta una escena de dolor y de abatimiento en la que Margaret parecía haber envejecido diez años tras haber pasado la noche sin dormir, «Les arrugues del front i les que lo voltaven els ulls, abans finíssimes, s'havien convertit en petits solcs, como si les manetes d'un rellotge fins llavors aturades sobre la seva pell, haguessin volgunt recuperar de cop el temps perdut, assenyalant amb la seva marca la veritat terrible dels anys» ${ }^{124}$. Los años que, señala Riera, no pasan igual para hombres que para mujeres pues «ser mujer y ser vieja son dos componentes negativos. [...] una mujer de cincuenta años es ya considerada vieja y, por tanto, las personas viejas son casi transparentes, no existen y no existen prácticamente» ${ }^{125}$. Su personaje, sin embargo, se vale de su estatus social y profesional para ser visible.

La profesionalidad de la subinspectora Manuela Vázquez también rompe con los estereotipos; una mujer «més aviat menuda i simpatica, d'una gran afabilitat però sense pèls a la llengua» ${ }^{126}$, que había estudiado psicología y estaba especializada en violencia de género. Habiendo sido primero policía nacional antes de entrar en el cuerpo de los Mossos d' Esquadra, «acostumava a encertar, quasi sempre amb un primer cop d' ull, si les acusaciones presentades eren certes o falses $»{ }^{127}$. Consciente de la similitud de su nombre con el del fallecido escritor catalán, tiene en casa novelas de la serie Carvalho, si bien, puntualiza, éstas eran de su marido. Sus estudios universitarios y su condición de mujer la ayudan a tranquilizar a las señoras Cremona y Hogarth de un modo que ninguno de sus colegas varones puede. Pese a su edad, sus conocimientos no se han quedado estancados, sino que sabe usar herramientas digitales y, además, tiene una ayudante más experta en los accesos remotos a ordenadores que la protagonista de Los hombres que no amaban a las mujeres, del autor y periodista de conciencia social sueco Stieg Larsson. Al contrario que Carvalho, que deja Barcelona porque ya no se siente identificado con sus cambios, Manuela avanza con la sociedad y hacía tiempo que pensaba que «en els nous temps democràtics la policia autonòmica estava disposada a acceptar que

\footnotetext{
${ }^{122}$ C. Riera (2011), p. 65.

${ }^{123}$ C. Riera (2011), p. 66.

${ }^{124}$ C. Riera (2011), p. 129.

${ }^{125}$ P. Farrington (200), p. 84.

${ }^{126}$ C. Riera (2011), p. 45.

${ }^{127}$ C. Riera (2011), p. 43.
} 
no tot era blanc o negre que havia un altre color entremig, que participava d'ambdós. Potser convenia apostar pel gris, el color de matisos i fins i tot del consens» ${ }^{128} \mathrm{y}$, con ese espíritu, y distanciándose de las imágenes de la policía anteriores, se mueve en un mundo en el que todavía son «els homes els que duien la veu cantant ${ }^{129}$, pero en el que sabe ganarse el respeto tanto de las madres de las víctimas, como de las profesoras, de sus compañeros e incluso de los inspectores.

El inspector Josep Lluçanès es el único miembro de la policía que se asemeja un poco a los personajes del cuerpo de Vázquez Montalbán o de Mendoza. De mentalidad machista, cuando coge el relevo de la investigación le pide a Vázquez que continúe con ella pensando que, aparte de no conocer a las señoras Cremona y Hogarth, dada «la seva decantació sexual, prefiririem, com a mal menor, les policies dones. Aizí li ho féu saber a la sotsinspectoram amb un somriure mir irònic» a lo que la subinspectora le responde que, en su opinión, el sexo de los policías es indiferente, «El que vole és que siguem eficients i, ja que no hem pogut trobar la Laura viva, que almenys trobem qui l'ha morta» ${ }^{130}$, dejando patente cuáles son las prioridades para ambos. Para un hombre alto, atractivo y seguro de sí mismo, con cierto aire de perdonavidas, el hecho de tener al lado a una mujer «de cara redona, nas de patata, ulls miops, més aviat menuda, de carnes curtes i grassoneta ${ }^{131}$ seguramente percibe a Vázquez como a una inferior, tal vez incluso despreciable, o así se lo imagina ella. Su mentalidad tradicional va acompañada del típico complejo de inferioridad que, en este caso, viene asociado a la única referencia que se hace del pasado en la novela, el de la policía franquista, junto al sentimiento catalanista. Tras hablar con las madres de Laura, Lluçanès estaba convencido de que las señoras despreciaban a la policía española y de que metían a la catalana en el mismo saco, tachándola de «inoperant, corrupta i no gens democràtica ${ }^{132}$. Para Manuela, que las señoras no hicieran preguntas acerca de la investigación de la muerte de Laura no tiene nada que ver con tales prejuicios, y aclara que «Si a la meva filla li passés el que li ha passat a la Laura, crec que em tiraria per la primera finestra que trobés oberta. No ho podria resistir. Entenc l'apatia de les senyores, entenc que res no els importi. Encara que detinguem l'assassí això no farà que la Laura ressusciti» ${ }^{133}$, atendiendo a la cuestión humana y prescindiendo de prejuicios pasados. La Barcelona que presenta la escritora mallorquina carece de un Pedrell, un Savolta o un Lepprince, y los únicos personajes que buscan medrar todo lo posible en la escala social usan otros medios, como Lluçanès, que soñaba

${ }^{128}$ C. Riera (2011), p. 73.
${ }^{129}$ C. Riera (2011), p. 24.
${ }^{130}$ C. Riera (2011), p. 131.
${ }^{131}$ C. Riera (2011), p. 132.
${ }^{132}$ C. Riera (2011), p. 136.
${ }^{133}$ C. Riera (2011), p. 136. 
con que tal vez, «quan arribès a comissari, ho li dedicarien un carrer» ${ }^{134}$, o como el rector dimisionario, a quien lo que más le preocupaba era la humillación de haber pasado a la historia de la Autónoma, donde había llevado una carrera brillante, como «el rector dels assassinats» ${ }^{135}$. Entre los políticos, el conseller de educación desea «poder influir perquè el nou rector fos de la seva corda o al menys mès simpatizant que el d' ara» y el conseller de interior pretende abrir un debate a nivel estatal para «parlar del paper de la universitat, potser una institució obsoleta, innecesària en els temps que corren ${ }^{136}$, desvelando sus verdaderas intenciones. Sus ricos no son especuladores o explotadores, sino mujeres trabajadoras, con posición social, y rompiendo normas.

Esta ciudad tampoco está llena de fluidos y olores, ni de castañas ni de fritos, ni de laberínticas calles, ni de descripciones oscuras. Reducida a unos cuantos nombres de locales y de barrios reales, prima la descripción de las emociones y de la crisis de valores, ante la que quiere ofrecer «un componente moral, como lo había, por ejemplo, en la obra de Baudelaire. No se trata de dar al lector normas de conducta, sino de mostrar nuestra perplejidad ante la condición humana» ${ }^{137}$, como ante unos jóvenes que buscan la diversión y el enfrentamiento con la policía y con la universidad, pero no su mejora personal pese a disfrutar de unas condiciones mucho mejores que las antes analizadas. Donde sí encontramos similitudes es en la crítica del abandono de los valores y los ideales, simbolizados en un desasosegado Carvalho, ironizados por un loco detective sin nombre, y reducidos a unos miserables huertos rodeados de basura y cultivados por un loco que dejó la abogacía. Los tres autores presentan la ciudad como reflejo de la conciencia urbana y prefieren este retrato al whodunnit propio de la novela negra estadounidense. A ninguno le gusta la ciudad, mantienen esa relación de amor odio, y mientras que el primero la describe con un desasosiego creciente y el segundo opta por la locura para describirla, Riera nos la muestra por medio de la sensibilidad y las emociones de, especialmente, dos mujeres, una subinspectora y una profesora universitaria que nos muestran un lado más positivo de la condición humana.

\section{Obras citadas}

ARANDA, Quim: «Qué pensa Manuel Vázquez Montalbán», Dèria, 1995.

BALIBREA EnRíQuez, Mari Paz: En la tierra baldía. Manuel Vázquez Montalbán y la izquierda española en la postmodernidad, Barcelona, El Viejo Topo, 1999.

\footnotetext{
${ }^{134}$ C. Riera (2011), p. 197.

${ }^{135}$ C. Riera (2011), p. 220.

${ }^{136}$ C. Riera (2011), p. 221.

${ }^{137}$ P. Farrington (2000), p. 82.
} 
BoATWRIGHT, D. y E. UCELAY DA CAl: «La dona del 'Bariro Chino'. La imatge del baixos fons i la revista 'El Escándalo'» L'Avenc, 76 (1984), pp 26-34.

CASSANI, A: Le Barcelone perdute di Pepe Carvalho, Milano, Ed. Unicopli, 2000.

COLMEIRO, José F: La novela policíaca española: teoría e historia crítica, Barcelona, Anthropos, 1994.

FARRINGTON, Pat: «Documenta. Interviews with Ana María Matute and Carme Riera», Journal of Iberian and Latin American Studies, 6, 1, (2000), pp. 7589.

ForgagCS, D: A Gramsci Reader, Londres, Lawrence and Wishart, 1988.

GAZARIAN GAUTIER, Marie-Lise : «Eduardo Mendoza», en Interviews with Spanish Writers, Elmwood Park, Dalkey Archive Press, 1991, pp. 201-7.

HART, Patricia: The Spanish Sleuth: The Detective in Spanish Fiction, Rutherford, NJ, Fairleigh Dickenson UP, 1987.

HARVEY, David: The Urban Experience, Baltimore, Johns Hopkins UP, 1989.

JAMESON, Frederic: The Political Unconscious: Narrative as Socially Symbolic Act, London, Methuen, 1981.

MARTÍNEZ ESCRIBÀ, A. «Análisis de un escenario negro: Barcelona como identidad literaria», en Álex Martínez Escibá \& Javier Sánchez Zapatero (Eds): Geografías en Negro. Escenarios del género criminal, Barcelona, Montesinos, 2009.

MCNEILL, Donald: Urban Change and the European Left: Tales from the New Barcelona, London and New York, Routledge, 1999.

MENDOZA, Eduardo: La verdad sobre el caso Savolta, Barcelona, Seix Barral, 1975.

---. El misterio de la cripta embrujada, Barcelona, Seix Barral, 1979.

---. El laberinto de las aceitunas, Barcelona, Seix Barral, 1982.

---. La ciudad de los prodigios, Barcelona, Seix Barral, 1986.

-----: Una comedia ligera, Barcelona, Seix Barral, 1996.

MORÁN, Gregorio: El precio de la transición. Una interpretación diferente y radical del proceso que condujo a España de la dictadura a la democracia, Barcelona, Planeta, 1991.

Moreno, Eduard y Manuel VÁzQuez MontAlBÁN: Barcelona, cap a on vas? Diàlegs per a una altra Barcelona, Barcelona, Llibres de l'Índex, 1991.

Pugovel, Sandra J.: «Pepe Carvalho and Spain: A Look at the Detective Fiction of Manuel Vázquez Montalbán», Monographic Review/ Revista Monográfica, 3. 1-2 (1987), pp. 261-267

RAMÓN GARCÍA, Emilio: «La esclavitud del discurso y la liberación de la memoria en Por el cielo y más allá», Lectora. Revista de Dones $i$ Textualitat, 11 (2006), pp. 215-233.

-----: De las olimpiadas de Barcelona a la ley de la memoria histórica: La re-visión de la historia en la novela histórica española, Murcia, Nausícaä, 2007. 
RESINA, Joan Ramón: El cadáver en la cocina: la novela criminal en la cultura del desencanto, Barcelona, Anthropos, 1997.

RIERA, Carme: Natura quasi morta, Barcelona, Edicions 62, 2011

SANTANA, Mario: «Manuel Vázquez Montalbán's Los mares del Sur and the Incrimination of the Spanish Transition», Revista de Estudios Hispánicos, 34.3 (2000), pp. 535-559.

SARRIAS, Cristóbal: «Barcelona, retratada por Eduardo Mendoza», Ya (21 mayo1986).

VÁZQueZ MonTALBÁN, Manuel: Yo maté a Kennedy. Barcelona, Planeta, 1972

-----: La soledad del mánager, Barcelona: Planeta, 1977.

-----: Los mares del Sur, Barcelona, Planeta, 1979.

-----: Asesinato en el comité central, Barcelona, Planeta, 1981.

-----: Los pájaros de Bangkok, Barcelona, Planeta, 1983.

----- \& Jaume FUSTER: Diàlegs a Barcelona, Barcelona, Laia, 1985.

-----: «Regalo de la casa, de Juan Madrid: el realismo no es lo que era», Ínsula, 23 (1987 a), pp. 488-489.

-----: «Desde los tejados», Historias de padres e hijos, Barcelona, Planeta, (1987b), pp. 9-62.

-----: Asesinato en Prado del Rey y otras historias sórdidas, Barcelona, Planeta, $1987 \mathrm{c}$.

-----: El delantero centro fue asesinado al atardecer, Barcelona, Planeta, 1989.

-----: El laberinto griego, Barcelona, Planeta, 1991.

----: Sabotaje Olímpico, Barcelona, Planeta, 1993.

-----: Tatuaje, 1974. Barcelona, Planeta, 1995.

-----: Quinteto de Buenos Aires, Barcelona, Planeta 1997.

-----: La literatura en la construcción de la ciudad democrática, Barcelona, Crítica, 1998.

-----: Milenio Carvalho, I. Rumbo a Kabul, Barcelona, Planeta 2004 a.

-----: El hombre de mi vida, Barcelona, Planeta, 2004b.

-----: Milenio Carvalho, II. En las antípodas, Barcelona, Planeta, 2004c. 